\title{
Assessment of thyroid cancer risk in more than 334,000 patients with inflammatory bowel disease: a case-control study and a meta-analysis
}

\author{
Lihong Cao
}

\begin{abstract}
Background: Potential risk of thyroid cancer in patients with inflammatory bowel disease has not been well investigated. The aim of the study was to reveal the relationship between history of inflammatory bowel disease and risk of thyroid cancer.

Methods: First, 1392 patients with inflammatory bowel disease and 1392 controls were included in a case-control study. All patients did not receive immunosuppressive therapy. A multivariate logistic regression analysis was adopted to determine the relationship between history of inflammatory bowel disease and risk of thyroid cancer. Second, a literature search was performed and eight articles were collected. Pooled odds ratios with $95 \%$ confidence intervals were reported for relevant risk estimates in fixed or random effect model.

Results: In the case-control study, thyroid cancer was more common in patients with inflammatory bowel disease than in controls $(P=0.032)$. After Bonferroni correction, association of thyroid cancer risk with history of total inflammatory bowel disease or its two subtypes was not found. In the meta-analysis, patients with total inflammatory bowel disease or ulcerative colitis showed an increased risk of thyroid cancer, but patients with Crohn's disease did not. Furthermore, inflammatory bowel disease patients with immunosuppressive therapy showed an increased risk of the cancer, but patients without immunosuppressive therapy did not have this finding.

Conclusions: Risk of thyroid cancer probably elevates in patients with inflammatory bowel disease. Inflammatory bowel disease (particularly ulcerative colitis) itself and use of immunosuppressant might contribute to the development of the cancer.
\end{abstract}

Keywords: Crohn's disease, Immunosuppressant, Inflammatory bowel diseases, Thyroid neoplasms, Ulcerative colitis

\section{Background}

Thyroid cancer (TC) is one kind of endocrine tumors, which originates in the tissue of thyroid gland [1]. Papillary thyroid carcinoma (PTC) is the most common histological subtype and accounts for more than $80 \%$ of TC cases. It often occurs at the age of 3565 years old and usually affects women more than men [2]. In recent years, incidence of TC has significantly increased [3]. Presently, there are more than three million TC patients around the world [3].

\section{Correspondence: caolihong2012@yeah.net}

Department of Ear-nose-throat, Tianjin Medical University General Hospital, No. 154, Anshan Road, Heping District, Tianjin 300052, China
Though prognosis of TC is not very poor, it still causes tens of thousands of deaths each year. Family history, radiation exposure, iodine intake abnormality, and obesity are major risk factors [4-7]. Other potential risk factors have not been well investigated.

Inflammatory bowel disease (IBD) including ulcerative colitis (UC) and Crohn's disease (CD) is a precancerous disease of colorectal cancer [8]. Besides, an increased risk of extra-intestinal cancer in IBD patients has been revealed by previous studies [9]. According to these findings, potential relationship between risk of TC and history of IBD has also been explored. Some studies reported that risk of $\mathrm{TC}$ was elevated in patients with

(c) The Author(s). 2018 Open Access This article is distributed under the terms of the Creative Commons Attribution 4.0 International License (http://creativecommons.org/licenses/by/4.0/), which permits unrestricted use, distribution, and 
IBD $[10,11]$, but other studies failed to do so [12, 13]. Thus, a firmed conclusion has not been drawn.

Therefore, we conducted a case-control study and a meta-analysis to evaluate the relationship between the risk of TC and the history of IBD and to further explore the mechanism involved.

\section{Methods}

\section{Case-control study}

Outpatients in Tianjin Binjiang Hospital between 1991 and 2000 enrolled in a health system database, which contained the huge data of these patients from baseline to 2015. All these outpatients signed the written informed consents and agreed to participate in a series of clinical studies including this study. A total of 1392 IBD patients (1022 UC patients, $370 \mathrm{CD}$ patients) were identified in this database according to ICD-9 codes (codes of CD: 555, 550.0, 555.1 and 555.9; codes of UC: 556, $556.0,556.1,556.2,556.3,556.5,556.6,556.8$, and 556.9) and served as the IBD group. All these patients did not have any kind of cancer on admission. And, 1392 ageand gender-matched patients with diverticulitis (codes of diverticulitis 62.11 and 562.13) were randomly collected from the database and served as control group.

Research data such as demographic information, personal history, medical history, treatment history, and other useful information from baseline to 2015 were collected from the database. Major endpoint was the development of PTC, and all the patients with PTC should be confirmed pathologically. Total follow-up period of these IBD patients were 27,448 person-years.

Most of the IBD patients received 5-ASA treatment and other supportive treatment. They did not receive any kind of biologics or immunosuppressant. They did not receive any surgical therapy.

History of smoking was defined as smoking ( $\geq 7$ cigarettes per week) for more than 6 months in one's life. History of drinking was defined as drinking alcohol $(\geq 3$ times per week) for more than 6 months in one's life. History of iodized salt intaking was defined as having iodized salt for more than 6 months in one's life. History of radiation exposure was defined as having radiation exposure ( $\geq 1$ time per month) for more than 6 months in one's life.

Difference of continuous variables was determined using independent sample $t$ test, and difference of categorical variables was determined using chi-square test. If a $P$ value was less than 0.05 , it was considered to be statistically significant. Relationship between the history of IBD and the risk of PTC was determined using multivariate logistic regression analysis. Odds ratios (ORs), 95\% confidence intervals (CIs), and $P$ values were reported. Bonferroni correction was adopted for multiple analyses, and Bonferroni corrected $P$ value was $0.004(0.05 / 12$ variables). If a $P$ value was less than 0.004 , it was statistically significant. These analyses were conducted using SPSS 17.0 (SPSS Inc., Chicago, IL, USA).

The study was separately approved by the ethics committee of Tianjin Medical University General Hospital (TMUGH-2016-0657) and Tianjin People's Hospital (Tianjin Binjiang Hospital) (TJRMYY-2016-087).

\section{Meta-analysis}

A structured literature search in MEDLINE/PubMed, EMBASE, Web of Science, and Cochrane Database of Systematic Reviews was conducted between January 1998 and December 2017. Search parameters were "Thyroid Cancer" [Title/Abstract], "Thyroid Neoplasms" [MeSH Terms], "Inflammatory Bowel Disease" [Title/Abstract], "Inflammatory Bowel Diseases" [MeSH Terms], "Ulcerative Colitis" [Title/Abstract], "Colitis, Ulcerative" [MeSH Terms], "Crohn's Disease" [Title/Abstract], "Crohn Disease" [MeSH Terms] and their combinations.

Inclusion criteria were listed as follows: (1) There were IBD group and control group in each study. (2) Number of TC patients in each group was reported. Only English articles were included. Subsequently, references in the included articles were searched. If any reference met the inclusion criteria, it was also adopted.

Two trained reviewers independently performed the data selection according to a predefined survey form, which had several contents: first author, year of publication, country, study design, age at diagnosis, gender, period of follow-up, use of immunosuppressant, size of study, and so on. All data were double entered.

Our meta-analysis was conducted according to the recommendations from the Cochrane Collaboration and the Quality of Reporting of Meta-analyses guidelines $[14,15]$. The fourfold table data (events/total in group one, events/total in group two) of each included study were input to a data matrix in Review Manager Version 5.2 (The Cochrane Collaboration, Software Update, Oxford). If $P$ values for heterogeneity $>0.05$, the results were performed by fixed effects method. If not, the random effects model was adopted. Then, OR and $95 \% \mathrm{CI}$ were reported. It was statistically significant, if the 95\% CI did not include the value one.

The study adopted three strategies to ensure the research quality. (1) Funnel plot obtained by Review Manager Software was used to evaluate the publication bias [16, 17]. (2) Sensitivity analysis was performed. In this process, each included study was sequentially removed from the meta-analysis to measure its contribution to the overall effect size. (3) All 
studies in the meta-analysis were scored by the Newcastle-Ottawa Scale to assess their overall quality [18].

\section{Results}

\section{Case-control study}

In Table 1, there were 1392 patients with IBD and 1392 controls with diverticulitis in the case-control study. Compared with the controls, body mass index was higher in the IBD patients $(P<0.001)$. More IBD patients had history of smoking, radiation exposure, or benign thyroid nodule $(P<0.001, P<0.001, P<0.001)$. More IBD patients had family history of TC $(P<0.001)$. Furthermore, the development of PTC was more common in the IBD patients than in the controls $(P=0.032)$.

In Table 2, after adjusted for several confounding factors (i.e., age, gender, body mass index, smoking, drinking alcohol, iodized salt intaking, radiation exposure, benign thyroid nodule and family history of thyroid cancer), a multivariate logistic regression analysis reported that the history of smoking, radiation exposure, benign thyroid nodule, inflammatory bowel disease, or ulcerative colitis was associated with the increased risk of PTC (OR 3.81, 95\%CI 1.27 11.37, $P=0.016$; OR 5.37, 95\%CI 1.78 16.13, $P=0.003$; OR 9.22, 95\%CI 1.21 70.54, $P=$ 0.031; OR 3.70, 95\%CI 1.04 13.26, $P=0.044$; OR 4.12, $95 \%$ CI $1.12 \sim 15.24, P=0.033)$. Family history of TC was also related to the elevated risk of the cancer (OR 13.02, 95\%CI 4.47 37.97, $P<0.001)$. After Bonferroni correction, only history of radiation exposure and

Table 1 Characteristics of inflammatory bowel disease patients and controls in the case-control study

\begin{tabular}{|c|c|c|c|}
\hline & $\mathrm{IBD}$ & Control & $P$ value \\
\hline$\overline{\text { Total }(n)^{\mathrm{b}}}$ & 1392 & 1392 & - \\
\hline Male $(n)$ & 634 & 658 & 0.362 \\
\hline Age $(\text { years })^{b}$ & $37.0 \pm 5.8$ & $36.7 \pm 5.8$ & 0.454 \\
\hline BMI $\left(\mathrm{kg} / \mathrm{m}^{2}\right)^{\mathrm{a}}$ & $23.2 \pm 4.3$ & $22.4 \pm 4.3$ & $<0.001$ \\
\hline History of smoking $(n)$ & 604 & 296 & $<0.001$ \\
\hline History of drinking $(n)$ & 410 & 395 & 0.531 \\
\hline History of iodized salt intaking $(n)$ & 754 & 708 & 0.081 \\
\hline History of radiation exposure $(n)$ & 251 & 14 & $<0.001$ \\
\hline History of benign thyroid nodule $(n)$ & 1064 & 570 & $<0.001$ \\
\hline Family history of TC $(n)^{\mathrm{a}}$ & 135 & 22 & $<0.001$ \\
\hline Age at diagnosis of IBD (years) ${ }^{a}$ & $26.9 \pm 6.3$ & - & - \\
\hline Duration of IBD on admission (years) & $10.1 \pm 2.8$ & - & - \\
\hline Extraintestinal manifestations $(n)$ & 708 & - & - \\
\hline 5-ASA treatment $(n)^{\mathrm{a}}$ & 1334 & - & - \\
\hline PTC development $(n)^{\mathrm{a}}$ & 11 & 3 & 0.032 \\
\hline
\end{tabular}

${ }^{a} B M I$ Body mass index, IBD inflammatory bowel disease, 5-ASA 5-aminosalicylic acid, PTC papillary thyroid carcinoma, TC thyroid cancer

${ }^{b}$ Categorical and continuous variables were separately showed by frequency and mean \pm standard deviation family history of $\mathrm{TC}$ reached the Bonferroni-corrected level of statistical significance.

\section{Meta-analysis}

As shown in Fig. 1, during the literature search using the parameters described above, 411 potential articles were found. Their abstracts were carefully reviewed, and 339 articles were directly excluded from the meta-analysis. Major reasons were that they were clinical studies with other topic (205), reviews (53), case reports (34), articles in other languages (27), or basic studies (20). Full texts of the remaining 72 articles were collected and reviewed. Among them, six articles focusing on this topic without required data, seven duplicate articles, and 52 articles focusing on other topics were excluded from the meta-analysis. Then, seven articles were included [11, 13, 19-23]. Their references were researched, and no suitable article was found. Meanwhile, our case-control study was also adopted. Thus, a total of eight studies were included in the meta-analysis.

Major characteristics of the included studies are presented in Table 3. There were 334,015 patients with IBD in the meta-analysis. The study with the largest sample size had 289,935 IBD patients, and the study with the smallest sample size had 374 patients. During the follow-up of more than 339,558 person-years, 244 patients had suffered from TC. Though time range of the literature search was 1998-2017, most of the included articles were published in the last 5 years. Improved detection for TC in the recent years was believed to be one of the possible reasons to explain this phenomenon. Five studies had normal controls, and the other three studies had patient controls with diverticulitis.

In Fig. 2, eight studies focused on the relationship between the history of IBD and the risk of TC in the patients. The fixed-effect pooled OR was 1.75 (95\%CI 1.48 2.07, $P$ for heterogeneity $=0.31$ ). After excluding our study, the fixed-effect pooled OR was 1.72 (95\%CI 1.45 2.04, $P$ for heterogeneity $=0.33$ ).

Five studies explored the possible association between the history of UC and the risk of TC, and the fixed-effect pooled OR was $1.62(95 \% \mathrm{CI} 1.26 \sim 2.09, P$ for heterogeneity $=0.25$ ) (Fig. 2). After excluding our study, the fixed-effect pooled OR was 1.54 (95\%CI 1.19 2.00, $P$ for heterogeneity $=0.32$ ).

Six studies showed the relationship between the history of $\mathrm{CD}$ and the risk of TC. The fixed-effect pooled OR was 1.41 (95\%CI $0.91 \sim 2.18, P$ for heterogeneity $=0.65$ ) (Fig. 2). After excluding our study, the fixed-effect pooled OR was 1.36 (95\%CI $0.86 \sim 2.14, P$ for heterogeneity $=0.57$ ).

In the subgroup analysis, the data were separately stratified by several factors, such as gender, race, case type, control type, use of immunosuppressant, and 
Table 2 Association of several variables with risk of papillary thyroid carcinoma in the case-control study

\begin{tabular}{|c|c|c|c|c|c|c|c|}
\hline Group & Subgroup & PTC $^{a}$ & Total & $\begin{array}{l}\text { Univariate } \\
\text { OR }(95 \% C l)^{a, b}\end{array}$ & $\begin{array}{l}\text { Univariate } \\
P \text { value }{ }^{c}\end{array}$ & $\begin{array}{l}\text { Multivariate } \\
\text { OR }(95 \% \text { Cl) }\end{array}$ & $\begin{array}{l}\text { Multivariate } \\
P \text { value }^{c} \\
\end{array}$ \\
\hline \multirow[t]{2}{*}{ Gender } & Female & 9 & 1492 & Reference & & Reference & \\
\hline & Male & 5 & 1292 & $0.64(0.20 \sim 1.92)$ & 0.425 & $0.65(0.21 \sim 1.93)$ & 0.424 \\
\hline \multirow[t]{2}{*}{ Age (years) } & $<36.9$ years & 6 & 1428 & Reference & & Reference & \\
\hline & $\geq 36.9$ years & 8 & 1356 & $1.41(0.49 \sim 4.06)$ & 0.529 & $1.42(0.49 \sim 4.07)$ & 0.528 \\
\hline \multirow[t]{2}{*}{ BMI $\left(\mathrm{kg} / \mathrm{m}^{2}\right)^{\mathrm{a}}$} & $<22.8 \mathrm{~kg} / \mathrm{m}^{2}$ & 5 & 1408 & Reference & & Reference & \\
\hline & $\geq 22.8 \mathrm{~kg} / \mathrm{m}^{2}$ & 9 & 1376 & $1.85(0.61 \sim 5.54)$ & 0.272 & $1.86(0.62 \sim 5.54)$ & 0.271 \\
\hline \multirow[t]{2}{*}{ History of smoking } & Absent & 5 & 1884 & Reference & & Reference & \\
\hline & Present & 9 & 900 & $3.80(1.27 \sim 11.36)$ & 0.017 & $3.81(1.27 \sim 11.37)$ & 0.016 \\
\hline \multirow[t]{2}{*}{ History of drinking } & Absent & 7 & 1979 & Reference & & Reference & \\
\hline & Present & 7 & 805 & $2.47(0.86 \sim 7.07)$ & 0.092 & $2.48(0.87 \sim 7.08)$ & 0.092 \\
\hline \multirow[t]{2}{*}{ History of $|\mathrm{S}|^{\mathrm{a}}$} & Absent & 4 & 1322 & Reference & & Reference & \\
\hline & Present & 10 & 1462 & $2.26(0.72 \sim 7.24)$ & 0.167 & $2.27(0.72 \sim 7.25)$ & 0.166 \\
\hline \multirow[t]{2}{*}{ History of RE ${ }^{a}$} & Absent & 9 & 2519 & Reference & & Reference & \\
\hline & Present & 5 & 265 & $5.36(1.78 \sim 16.12)$ & 0.003 & 5.37 (1.78 16.13) & 0.003 \\
\hline \multirow[t]{2}{*}{ History of BTN ${ }^{a}$} & Absent & 1 & 1150 & Reference & & Reference & \\
\hline & Present & 13 & 1634 & $9.21(1.20 \sim 70.53)$ & 0.032 & $9.22(1.21 \sim 70.54)$ & 0.031 \\
\hline \multirow[t]{2}{*}{ Family history of $\mathrm{TC}^{\mathrm{a}}$} & Absent & 8 & 2627 & Reference & & Reference & \\
\hline & Present & 6 & 157 & 13.01 (4.47 37.96) & $<0.001$ & 13.02 (4.47 37.97) & $<0.001$ \\
\hline \multirow[t]{2}{*}{ History of IBD ${ }^{a}$} & Control & 3 & 1392 & Reference & & Reference & \\
\hline & $\mathrm{IBD}$ & 11 & 1392 & 3.69 (1.04 13.25) & 0.045 & $3.70(1.04 \sim 13.26)$ & 0.044 \\
\hline \multirow[t]{2}{*}{ History of $C D^{a}$} & Control & 3 & 1392 & Reference & & Reference & \\
\hline & $C D$ & 2 & 370 & $2.52(0.43 \sim 15.12)$ & 0.313 & $2.53(0.43 \sim 15.13)$ & 0.313 \\
\hline \multirow[t]{2}{*}{ History of $U C^{a}$} & Control & 3 & 1392 & Reference & & Reference & \\
\hline & UC & 9 & 1022 & $4.11(1.12 \sim 15.23)$ & 0.034 & $4.12(1.12 \sim 15.24)$ & 0.033 \\
\hline
\end{tabular}

${ }^{\mathrm{a}} B M I$ body mass index, ISI iodized salt intaking, $R E$ radiation exposure, $B T N$ benign thyroid nodule, IBD inflammatory bowel disease, UC ulcerative colitis, $C D$ Crohn's disease, TC thyroid cancer, PTC papillary thyroid carcinoma, OR odds ratio, Cl confidence interval

bunivariate analysis was not adjusted by potential confounding factor. Multivariate analysis was adjusted by age, gender, body mass index, smoking, drinking alcohol, iodized salt intaking, radiation exposure, benign thyroid nodule, and family history of thyroid cancer

${ }^{c}$ Bonferroni correction was adopted for multiple analyses, and Bonferroni corrected $P$ value was $0.004(0.05 / 12$ variables). If a $P$ value was less than 0.004 , it was statistically significant

number of IBD patients. The results were showed in Table 4. The meta-analysis with hospital-based or small sample size (less than 10,000 cases) studies did not report any statistically significant results, revealing that study design had great influence on the result.

Jung et al. and So et al. reported that $35.3 \%$ and $40.0 \%$ of the IBD patients separately in their studies received the immunosuppressant, and these two studies were defined as "ever use" studies $[13,19]$. Sonu et al. in their study and our case-control study reported that the IBD patients did not adopt any kind of immunosuppressant before the development of TC, and these studies were defined as "never use" study [22]. Then, a subgroup analysis was done (Table 4). The IBD patients who ever received the immunosuppressant showed the increased the risk of TC, but the patients who never received these drugs did not show any change of the TC risk compared with the controls.

\section{Discussion}

At present, only a few clinical and epidemiological studies focused on the risk of TC in IBD patients around the world. Most of the studies were based on their national health or medical insurance databases and had a huge sample size $[11,13,19,20,23]$. Because many potential confounding factors were not taken into account, these studies actually conducted an unadjusted analysis. In addition, there were two hospital-based studies. One was from Yano et al. and examined all kinds of cancers in CD patients [21]. Another one came from Sonu et al, and their results were only adjusted by age and gender [22]. Both the studies did not have a well-adjusted design. Therefore, we carried out this case-control study, which had taken into account many confounding factors, such as family history, radiation exposure, iodine intake 


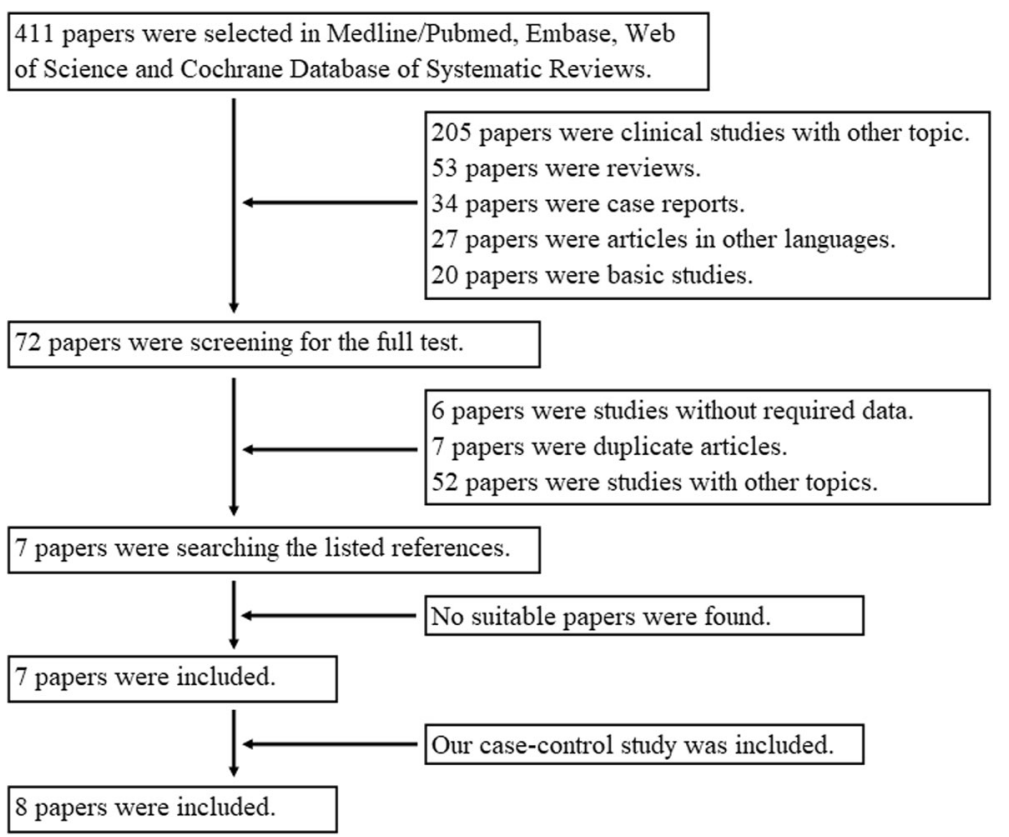

Fig. 1 Paper checklist and flowchart in the literature search

abnormality, and obesity. We believed that our study might supplement the shortcomings of the previous studies.

Incidence of $\mathrm{TC}$ in the case-control study seemed to be higher than many previous studies $[19,20]$. Possible reasons were listed as follows: First, TC was a relatively quiet tumor, and could be asymptomatic for a long time. Second, due to the improvement of health consciousness, many local people began to receive regular physical examination. Third, great progress had been made in diagnostic technology for TC. So, many cases of TC were found in recent years. The incidence of the cancer might be underestimated in the previous studies $[19,20]$.
Based on the adjusted analysis, the case-control study reported that the patients with IBD or its subtype UC had a more than 2-time or 3-time increased risk of PTC compared with the controls. However, these results did not reach the Bonferroni-corrected statistical significance.

In the meta-analysis, there were eight case-control studies with a total of 334,015 IBD patients. All the eligible studies had been included. Based on the pooled results, the patients with IBD showed a $45-100 \%$ increased risk of TC and the patients with its subtype UC showed a $20-100 \%$ increased risk of TC compared with the controls. The pooled results demonstrated the significant increase of the cancer risk in patients with IBD

Table 3 Characteristics of included studies in the meta-analysis

\begin{tabular}{|c|c|c|c|c|c|c|c|c|c|}
\hline $\begin{array}{l}\text { First } \\
\text { author }\end{array}$ & Year & Country & $\begin{array}{l}\text { No. of IBD } \\
(n)^{a}\end{array}$ & $\begin{array}{l}\text { IBD male } \\
(n)\end{array}$ & $\begin{array}{l}\text { IBD age at diagnosis } \\
\text { (years) }\end{array}$ & IBD type & $\begin{array}{l}\text { No. of controls } \\
(n)\end{array}$ & $\begin{array}{l}\text { Control } \\
\text { type }\end{array}$ & $\begin{array}{l}\text { Quality } \\
\text { score }\end{array}$ \\
\hline This study & 2018 & China & 1392 & 634 & Mean 26.9 & $\begin{array}{l}\text { Single } \\
\text { center }\end{array}$ & 1392 & Patient & 7 \\
\hline Jung & 2017 & Korea & 15,291 & 9743 & Mean 38.6 & Population & $1,529,100$ & Normal & 7 \\
\hline So & 2017 & China & 1603 & 893 & Median CD 40/UC $53^{a}$ & Population & 160,300 & Normal & 7 \\
\hline Wadhwa & 2016 & USA & 289,935 & 125,635 & Mean 50.1 & Population & 315,145 & Patient & 7 \\
\hline Jussila & 2013 & Finland & 21,964 & 11,810 & NM & Population & $2,196,400$ & Normal & 7 \\
\hline Yano & 2013 & Japan & 770 & 531 & Mean 23.1 & $\begin{array}{l}\text { Single } \\
\text { center }\end{array}$ & 77,000 & Normal & 6 \\
\hline Sonu & 2013 & USA & 2686 & 913 & Mean 47.5 & $\begin{array}{l}\text { Single } \\
\text { center }\end{array}$ & 1638 & Patient & 6 \\
\hline Jess & 2004 & Denmark & 374 & 157 & NM & Population & 37,400 & Normal & 7 \\
\hline
\end{tabular}

a IBD inflammatory bowel disease, NM not mentioned, CD Crohn's disease, UC ulcerative colitis 


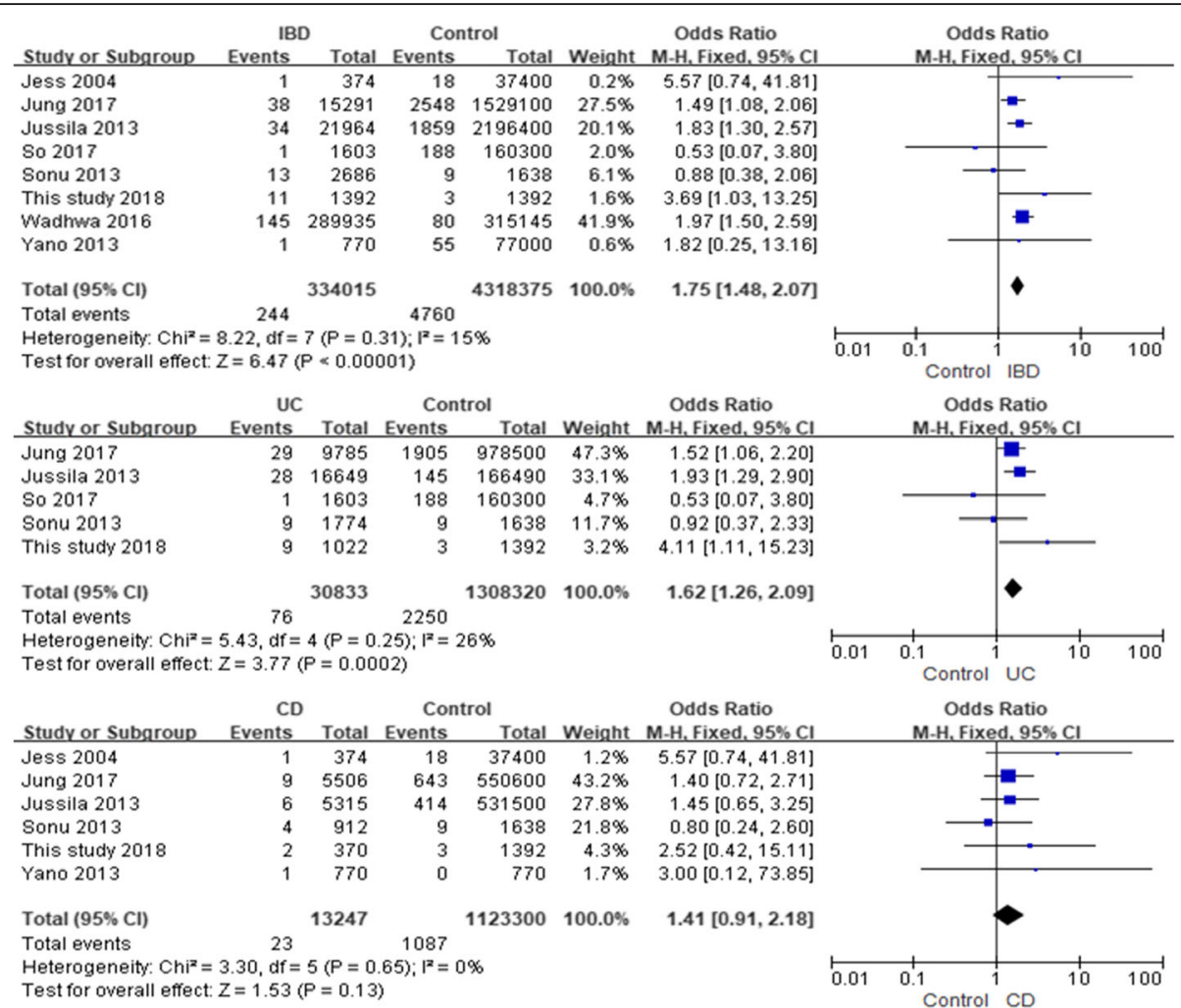

Fig. 2 Relationship between history of inflammatory bowel disease and risk of thyroid cancer in fixed effects model

Table 4 Results of meta-analysis in the subgroup

\begin{tabular}{|c|c|c|c|c|}
\hline Subgroup & No. of studies $(n)$ & No. of IBD $(n)^{a}$ & OR $(95 \% C l)^{a}$ & $P$ value for heterogeneity \\
\hline \multicolumn{5}{|l|}{ Gender } \\
\hline Male & 2 & 21,553 & $2.05(1.38 \sim 3.05)$ & 0.26 \\
\hline Female & 2 & 15,702 & $1.48(1.11 \sim 1.97)$ & 0.79 \\
\hline \multicolumn{5}{|l|}{ Race } \\
\hline Asian & 4 & 19,056 & 1.55 (1.15 2.08) & 0.39 \\
\hline Caucasian & 2 & 22,338 & $1.87(1.34 \sim 2.61)$ & 0.29 \\
\hline \multicolumn{5}{|l|}{ Case type } \\
\hline Population & 5 & 329,167 & $1.77(1.49 \sim 2.11)$ & 0.36 \\
\hline Hospital & 3 & 4848 & $1.50(0.78 \sim 2.88)$ & 0.18 \\
\hline \multicolumn{5}{|l|}{ Control type } \\
\hline Normal & 5 & 40,002 & $1.61(1.28 \sim 2.02)$ & 0.48 \\
\hline Patient & 3 & 292,621 & $1.89(1.47 \sim 2.44)$ & 0.12 \\
\hline \multicolumn{5}{|c|}{ Immunosuppressant } \\
\hline Ever use & 2 & 16,894 & $1.43(1.04 \sim 1.96)$ & 0.31 \\
\hline Never use & 2 & 4078 & $1.47(0.74 \sim 2.92)$ & 0.07 \\
\hline \multicolumn{5}{|c|}{ No. of IBD patients } \\
\hline$\geq 10,000$ & 3 & 327,190 & $1.79(1.50 \sim 2.14)$ & 0.42 \\
\hline$<10,000$ & 5 & 5433 & $1.39(0.78 \sim 2.48)$ & 0.19 \\
\hline
\end{tabular}

a IBD inflammatory bowel disease, $O R$ odds ratio, $C l$ confidence interval 
or its subtype UC. In the subgroup analysis, the relationship between the history of IBD and the risk of TC always existed in men, women, Asians, and Caucasians, suggesting that the increased risk of TC in IBD might not be a single race or gender problem.

To our knowledge, it was the first meta-analysis exploring the relationship between the history of IBD and the risk of TC. Pedersen et al. obtained an estimate of the risk of extra-intestinal cancer in CD and UC by performing a meta-analysis of population-based cohort studies and reported that the risk of upper gastrointestinal tract cancer, lung cancer, urinary bladder cancer, or skin cancer was significantly increased among patients with $\mathrm{CD}$, and the risk of liver-biliary cancer or leukemia was significantly increased in patients with UC [9]. However, only two cohort studies with not enough subjects focused on TC, and their pooled results did not demonstrate a relationship between the history of IBD and the risk of TC [9]. Another meta-analysis from Huai et al. explored the impact of IBD on cholangiocarcinoma, and suggested the risk of cholangiocarcinoma was significantly increased among IBD patients, especially in intrahepatic cholangiocarcinoma cases [24]. Though there were no positive or available results on $\mathrm{TC}$, both meta-analyses demonstrated the relationship between the history of IBD and the risk of extra-intestinal cancer.

In addition, the results of the case-control study were basically the same as those of the meta-analysis, though the Bonferroni-corrected results in the case-control study were not statistically significant. A possible explanation for the negative results after Bonferroni-correction was the lack of sample size. This explanation had been confirmed in the subgroup meta-analysis. The population-based studies in the subgroup meta-analysis reported a $50-110 \%$ increased risk of TC in the IBD patients. But, the studies with small sample size failed to do so.

At present, immunosuppressant became one common therapeutic drug for IBD. Some previous studies reported that the use of immunosuppressant increased the risk of cancer $[25,26]$. In particular, immunosuppressant caused lymphoproliferative disorder, which was related to the development of $\mathrm{TC}$ [26]. In the case-control study, the patients did not receive the immunosuppressant and provided a negative result. In the meta-analysis, the patients who ever use immunosuppressant showed an increased risk of TC, but the patients who never used the drug did not. So, the strategy of immunosuppressive therapy might be a possible carcinogenic factor for TC.

Radiation exposure was another important confounding factor. A previous study reported that the IBD patients frequently received X-ray or computed tomography examination, which was a potential hazard to the human body [27]. In the case-control study, the history of radiation exposure was related to the increased risk of the cancer. Therefore, excessive exposure to radiation in IBD patients probably contributed to the development of TC.

Potential role of IBD in the development of TC could not be completely negated. The meta-analysis found that the risk of TC was higher in the UC patients than in the $\mathrm{CD}$ patients. The case-control study supported it, though the results did not reach Bonferroni-corrected statistical significance. This finding apparently could not be explained by the use of immunosuppressant and excessive exposure to radiation, but could be partly explained by chronic inflammation in IBD. It was well known that the pathogenesis of UC and CD was not exactly the same. CD was clearly identified as a Th1 inflammation [28], and Th2 mainly improved the development of UC [29]. Interleukin-13 (IL-13) was the key Th2 cytokine, and affected epithelial tight junctions, apoptosis and cell restitution in UC [30]. IL-5 was another Th2 cytokine, which could attract eosinophils to intestinal tissue and caused tissue damage and intestinal inflammation in UC [31]. Furthermore, Th2 cytokines (IL-4, IL-5 and IL-13), but not Th1 cytokines, were implicated in the pathogenesis of TC. Simonovic et al. suggested that peripheral blood cells of differentiated TC patients produced significantly higher concentrations of Th2 cytokines (IL-5 and IL-13) than control subjects, and radioactive 131-I therapy led to reduced secretion of these Th2 cytokines [32]. Joshi et al. demonstrated that IL- 4 receptor- $\alpha$ (IL- $4 R \alpha$ ) was overexpressed in anaplastic TC and might represent a novel therapeutic target in this cancer [33]. Taken together, there was no enough evidence that IBD was an independent risk factor for TC, but IBD might provide an appropriate inflammatory environment and promote the development of the cancer.

Quality evaluation of the meta-analysis was conducted and mainly involved three aspects: participant selection, group comparability, and outcome assessment. All included studies received satisfactory scores (Table 3 ). Major results were based on the fixed effects model $(P$ values for heterogeneity were $>0.05$ ). So, included studies showed good homogeneity. Publication bias was an important problem and could not be ignored. As shown in Fig. 3, the studies created roughly funnel-shaped distributions and formed symmetric graphs. So, significant publication bias had not been detected.

"Reverse causality" might be a potential limitation in case-control study. But, the studies in our meta-analysis were nested case-control studies with follow-ups of 6000-236,000 person-years. "Recall bias" was another potential problem in retrospective study. But, all included studies obtained their research data from medical 


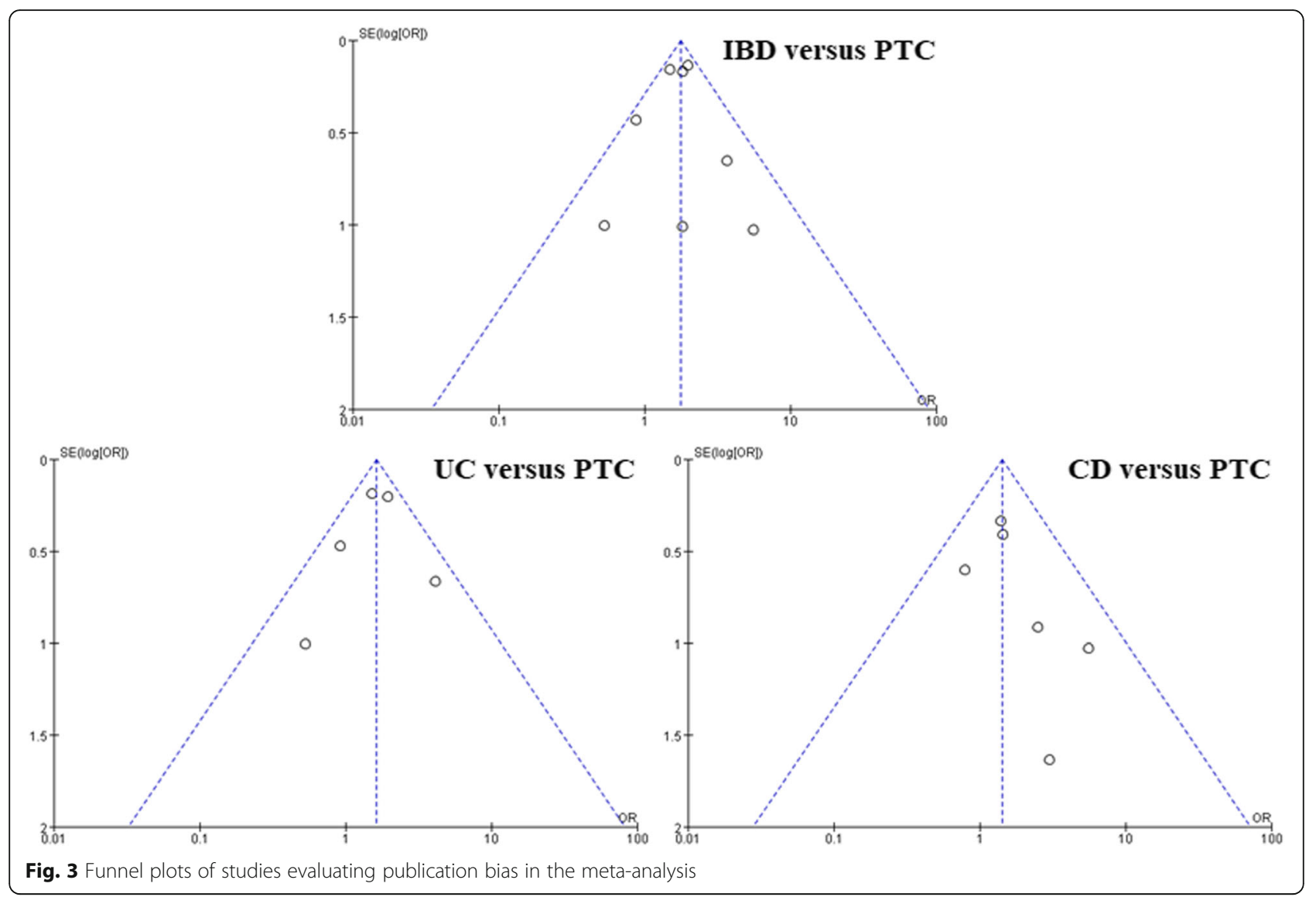

records or health data system. The cases of IBD and TC were collected according to ICD-10 system. So, we did not think these issues affected our results.

TC was classified into medullary cancer, follicular cancer, undifferentiated cancer, and PTC. The case-control study focused on the PTC patients. But, most of the included studies in the meta-analysis explored the association of IBD with total TC. This limitation might cause bias, though PTC was the most common tissue subtype and accounted for more than $80 \%$ of total TC cases. More research should be conducted in different tissue types of TC.

\section{Conclusions}

In conclusion, there were some defects in the current studies, but their achievements could be the basis for future research. Based on the results of our case-control study and meta-analysis, we suggested that the risk of TC probably elevated in patients with IBD, and this increase was more significant in its subtype UC. Inflammatory response of IBD itself, use of immunosuppressant and other undefined factors contributed to the development of TC. Well-adjusted and population-based studies should be conducted to verify our conclusion.

\section{Abbreviations}

CD: Crohn's disease; Cl: Confidence interval; IBD: Inflammatory bowel disease; >OR: Odds ratio; PTC: Papillary thyroid carcinoma; TC: Thyroid cancer; UC: Ulcerative colitis

\section{Acknowledgements}

I want to take this chance to thank to Dr. LQ (Tianjin Binjiang Hospital, Tianjin People's Hospital). In the process of data collection, he gives me many academic and constructive advices and helps me to correct my paper.

\section{Author's contribution}

$\mathrm{CL}$ collected, analyzed, and interpreted the data. Then, she wrote and approved the final manuscript.

Ethics approval and consent to participate

All subjects signed the written informed consents and agreed to participate in this case control study. The study was separately approved by the ethics committee of Tianjin Medical University General Hospital and Tianjin Binjiang Hospital.

Consent for publication Not applicable.

\section{Competing interests}

The author declares that she has no competing interests.

\section{Publisher's Note}

Springer Nature remains neutral with regard to jurisdictional claims in published maps and institutional affiliations. 
Received: 1 June 2018 Accepted: 31 August 2018

Published online: 10 September 2018

\section{References}

1. Burns WR, Zeiger MA. Differentiated thyroid cancer. Semin Oncol. 2010;37: 557-66.

2. Jonklaas J, Nogueras-Gonzalez G, Munsell M, Litofsky D, Ain KB, Bigos ST, et al. The impact of age and gender on papillary thyroid cancer survival. J Clin Endocrinol Metab. 2012;97:878-87.

3. Davies L, Morris L, Hankey B. Increases in thyroid cancer incidence and mortality. JAMA. 2017:318:389-90.

4. Leux C, Truong T, Petit C, Baron-Dubourdieu D, Guénel P. Family history of malignant and benign thyroid diseases and risk of thyroid cancer: a population-based case-control study in New Caledonia. Cancer Causes Control. 2012:23:745-55.

5. Takamura N, Orita M, Saenko V, Yamashita S, Nagataki S, Demidchik Y. Radiation and risk of thyroid cancer: Fukushima and Chernobyl. Lancet Diabetes Endocrinol. 2016;4:647.

6. Zimmermann MB, Galetti V. lodine intake as a risk factor for thyroid cancer: a comprehensive review of animal and human studies. Thyroid Res. 2015;8:8.

7. Oberman B, Khaku A, Camacho F, Goldenberg D. Relationship between obesity, diabetes and the risk of thyroid cancer. Am J Otolaryngol. 2015:36:535-41.

8. Harpaz N, Ward SC, Mescoli C, Itzkowitz SH, Polydorides AD. Precancerous lesions in inflammatory bowel disease. Best Pract Res Clin Gastroenterol. 2013;27:257-67

9. Pedersen N, Duricova D, Elkjaer M, Gamborg M, Munkholm P, Jess T. Risk of extra-intestinal cancer in inflammatory bowel disease: meta-analysis of population-based cohort studies. Am J Gastroenterol. 2010;105:1480-7.

10. Biancone L, Armuzzi A, Scribano ML, D'Inca R, Castiglione F, Papi C. Inflammatory bowel disease phenotype as risk factor for cancer in a prospective multicentre nested case-control IG-IBD study. J Crohns Colitis. 2016;10:913-24

11. Jussila A, Virta LJ, Pukkala E, Färkkilä MA. Malignancies in patients with inflammatory bowel disease: a nationwide register study in Finland. Scand J Gastroenterol. 2013;48:1405-13.

12. Biancone L, Zuzzi S, Ranieri M, Petruzziello C, Calabrese E, Onali S, et al. Fistulizing pattern in Crohn's disease and pancolitis in ulcerative colitis are independent risk factors for cancer: a single-center cohort study. Crohns Colitis. 2012;6:578-87.

13. So J, Tang W, Leung WK, Li M, Lo FH, Wong MTL, et al. Cancer risk in 2621 Chinese patients with inflammatory bowel disease: a population-based cohort study. Inflamm Bowel Dis. 2017;23:2061-8.

14. Clarke M, Horton R. Bringing it all together: Lancet - Cochrane collaborate on systematic reviews. Lancet. 2001;357:1728.

15. Stroup DF, Berlin JA, Morton SC, Olkin I, Williamson GD, Rennie D, et al. Meta-analysis of observational studies in epidemiology: a proposal for reporting. Meta-analysis Of Observational Studies in Epidemiology (MOOSE) group. JAMA. 2000;283:2008-12.

16. Egger M, Davey Smith G, Schneider M, Minder C. Bias in meta-analysis detected by a simple, graphical test. BMJ. 1997;315:629-34.

17. Egger M, Smith GD. Misleading meta-analysis. BMJ. 1995;311:753-4.

18. Athanasiou T, Al-Ruzzeh S, Kumar P, Crossman MC, Amrani M, Pepper JR, et al. Off-pump myocardial revascularization is associated with less incidence of stroke in elderly patients. Ann Thorac Surg. 2004;77:745-53.

19. Jung YS, Han M, Park S, Kim WH, Cheon JH. Cancer risk in the early stages of inflammatory bowel disease in Korean patients: a nationwide populationbased study. J Crohns Colitis. 2017;11:954-62.

20. Wadhwa V, Lopez R, Shen B. Crohn's disease is associated with the risk for thyroid Cancer. Inflamm Bowel Dis. 2016:22:2902-6.

21. Yano $Y$, Matsui T, Hirai F, Okado $Y$, Sato $Y$, Tsurumi $K$, et al. Cancer risk in Japanese Crohn's disease patients: investigation of the standardized incidence ratio. J Gastroenterol Hepatol. 2013;28:1300-5.

22. Sonu IS, Blonski W, Lin MV, Lewis J, Aberra F, Lichtenstein GR. Papillary thyroid cancer and inflammatory bowel disease: is there a relationship? World J Gastroenterol. 2013;19:1079-84.

23. Jess T, Winther KV, Munkholm P, Langholz E, Binder V. Intestinal and extraintestinal cancer in Crohn's disease: follow-up of a population-based cohort in Copenhagen County, Denmark. Aliment Pharmacol Ther. 2004;19:287-93.

24. Huai JP, Ding J, Ye XH, Chen YP. Inflammatory bowel disease and risk of cholangiocarcinoma: evidence from a meta-analysis of population-based studies. Asian Pac J Cancer Prev. 2014;15:3477-82.
25. Jiyad Z, Olsen CM, Burke MT, Isbel NM, Green AC. Azathioprine and risk of skin cancer in organ transplant recipients: systematic review and metaanalysis. Am J Transplant. 2016;16:3490-503.

26. Kandiel A, Fraser AG, Korelitz BI, Brensinger C, Lewis JD. Increased risk of lymphoma among inflammatory bowel disease patients treated with azathioprine and 6-mercaptopurine. Gut. 2005:54:1121-5.

27. Peloquin JM, Pardi DS, Sandborn WJ, Fletcher JG, McCollough CH, Schueler $\mathrm{BA}$, et al. Diagnostic ionizing radiation exposure in a population-based cohort of patients with inflammatory bowel disease. Am J Gastroenterol. 2008;103:2015-22

28. Brand S. Crohn's disease: Th1, Th17 or both? The change of a paradigm: new immunological and genetic insights implicate Th17 cells in the pathogenesis of Crohn's disease. Gut. 2009 Aug;58(8):1152-67.

29. Bamias G, Kaltsa G, Ladas SD. Cytokines in the pathogenesis of ulcerative colitis. Discov Med. 2011 May;11(60):459-67.

30. Heller F, Florian P, Bojarski C, Richter J, Christ M, Hillenbrand B, Mankertz J, Gitter AH, Bürgel N, Fromm M, Zeitz M, Fuss I, Strober W, Schulzke JD. Interleukin-13 is the key effector Th2 cytokine in ulcerative colitis that affects epithelial tight junctions, apoptosis, and cell restitution. Gastroenterology. 2005 Aug;129(2):550-64

31. Lampinen $M$, Carlson $M$, Sangfelt $P$, Taha $Y$, Thörn $M$, Lööf $L$, Raab $Y$, Venge P. IL-5 and TNF-alpha participate in recruitment of eosinophils to intestinal mucosa in ulcerative colitis. Dig Dis Sci. 2001 Sep;46(9):2004-9.

32. Simonovic SZ, Mihaljevic O, Majstorovic I, Djurdjevic P, Kostic I, Djordjevic OM, Teodorovic LM. Cytokine production in peripheral blood cells of patients with differentiated thyroid cancer: elevated Th2/Th9 cytokine production before and reduced Th2 cytokine production after radioactive iodine therapy. Cancer Immunol Immunother. 2015 Jan;64(1):75-82.

33. Joshi BH, Suzuki A, Fujisawa T, Leland P, Varrichio F, Lababidi S, Lloyd R, Kasperbauer J, Puri RK. Identification, characterization, and targeting of IL-4 receptor by IL-4-pseudomonas exotoxin in mouse models of anaplastic thyroid cancer. Discov Med. 2015 Nov;20(111):273-84.

\section{Ready to submit your research? Choose BMC and benefit from:}

- fast, convenient online submission

- thorough peer review by experienced researchers in your field

- rapid publication on acceptance

- support for research data, including large and complex data types

- gold Open Access which fosters wider collaboration and increased citations

- maximum visibility for your research: over $100 \mathrm{M}$ website views per year

At $\mathrm{BMC}$, research is always in progress.

Learn more biomedcentral.com/submissions 